\title{
Pisacano Leadership Foundation Names 2017 Pisacano Scholars
}

\section{Jane Ireland}

The Pisacano Leadership Foundation, the philanthropic arm of the American Board of Family Medicine (ABFM), recently selected its 2017 Pisacano Scholars. These 6 medical students follow in the footsteps of 108 scholar alumni who are practicing physicians and 20 current scholars who are enrolled in medical schools or family medicine residency programs across the country. The Pisacano Leadership Foundation was created in 1990 by the ABFM in tribute to its founder and first executive director, Nicholas J. Pisacano, MD (1924 to 1990). Each Pisacano Scholar has demonstrated the highest level of leadership, academic achievement, communication skills, community service, and character and integrity.

Victoria Boggiano, a 2017 Pisacano Scholar, is a fourth-year medical student at Stanford School of

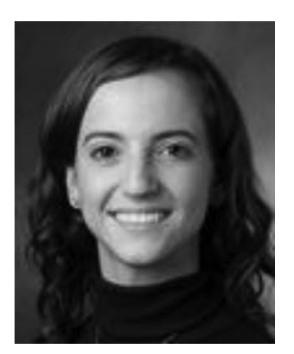

Medicine. Earlier this year she received her Master of Public Health from the University of California (UC)-Berkeley. Victoria graduated from Dartmouth College with degrees in Government and Biology.

Victoria received a number of scholarships at Dartmouth and was inducted into Phi Beta Kappa on graduation. As a junior, she was awarded a fellowship through the John Sloan Dickey Center for International Understanding which allowed her to travel to Vietnam that summer to intern with an organization in Hanoi called the Vietnam Sustainable Development Center. During her senior year, she received 2 more fellowships, allowing her to work with Save the Children in Vietnam and to also conduct a

Conflict of interest: The author is an employee of the ABFM. study on parents' perceptions of integration of $\mathrm{HIV}$-positive orphans into public schools in the $\mathrm{Ba}$ Dinh and Ba Vi districts in Hanoi, Vietnam.

After graduating from Dartmouth, Victoria spent a year working as a Community HealthCorps Navigator at a federally qualified health center in Maryland through the AmeriCorps program. In her role as the site's Women's Health Program Monitor, she and her colleagues provided contraceptive and preconception counseling to young women, worked with newly pregnant mothers in the organization's prenatal clinics, discussed infant care with mothers who had just delivered, and ran a support group for women in the community who were living with HIV/AIDS. On completing her year of service with AmeriCorps, she received a scholarship that was applied to her medical school tuition.

At Stanford, Victoria received a Traveling Scholars Fellowship that allowed her to travel to Vietnam to conduct a study on healthy behaviors of homeless youth living in Ho Chi Minh City. Victoria has also received scholarships from the California Academy of Family Physicians (CAFP) and Society for Teachers in Family Medicine. She is currently the regional coordinator of the Family Medicine Interest Group network and is a member and former cochair of both Stanford's Family Medicine Interest Group and Stanford's Primary Care Progress. Victoria has been involved with Longitudinal Community Health Advocacy Medical Partnerships (L-CHAMP) since her first year of medical school. This course places students in community health centers around the Palo Alto region. Victoria has worked in multiple settings through L-CHAMP and currently is beginning to develop her own panel of patients. She credits these early experiences in her medical school career with solidifying her commitment to Family Medicine.

Victoria hopes to spend her future career in family medicine working in urban underserved regions of the United States. She has a strong interest 
in obstetrics and gynecology (OB/GYN), and plans to pursue an OB/GYN fellowship after graduating from residency. She also hopes to apply the skills she learns in her training to the work she will continue to do abroad, particularly in Southeast Asia.

Geoff Gusoff, a 2017 Pisacano Scholar, is a fourth-year medical student at the Perelman School of Medicine at the University of Pennsylva-

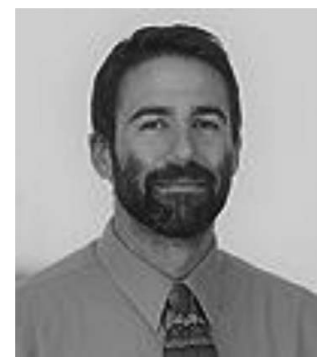
nia (Penn). He graduated magna cum laude from Brown University with a Bachelor of Arts in both Religious Studies and Public Policy, and was inducted into Phi Beta Kappa his senior year. Geoff received his Master of Theological Studies from Boston College and is now also completing his Master of Business Administration at The Wharton School at the University of Pennsylvania.

Geoff was awarded the Harry S. Truman Scholarship for Public Service, a $\$ 30,000$ scholarship for graduate studies awarded to 1 college junior from each state who has demonstrated exceptional leadership in the field of public service. He also received the President James Manning Medal for the Study and Practice of Religion and the Alfred H. Joslin Award in recognition of his leadership. During his freshman year, Geoff cofounded the student activist group Housing Opportunities for People Everywhere (HOPE), and helped lead it throughout college. The group worked alongside homeless activists seeking housing justice in Providence, Rhode Island. HOPE remains an active organization 13 years later.

After college, Geoff worked for a year as a Jesuit Volunteer at the Mental Health Advocacy Project in San Jose, California. He then volunteered for 10 months with Partners in Health in Lima, Peru before beginning graduate studies in theology at Boston College. While in Boston he worked as a Teacher-Organizer for Service Employees International Union. He then spent 7 months in El Salvador developing and implementing a financially sustainable computer literacy program based at a clinic for extremely low-income Salvadoran youth, and provided organizational consulting for 2 workerowned cooperatives.

Geoff has received multiple scholarships for graduate school and medical school, including the Twenty-First Century Scholarship. This fulltuition medical school scholarship is awarded to students who have demonstrated leadership, outstanding academic performance and achievement, and commitment to interests other than academic work. Since the beginning of medical school, Geoff has served as a volunteer organizer for the Philadelphia Workers Association, helping to develop an immigrant-owned construction cooperative for day laborers. He served as cocoordinator of the Family Medicine Interest Group and cocoordinator of the Social Justice Health Care group at Penn. As cofounder of the Social Justice Health Care group at Penn, Geoff has brought together students and professionals in medicine, nursing, social work, and other fields to explore ways that health care professionals and institutions can advance social justice aims.

Geoff's long-term goal is to work as a family physician at a community health center, accompanying patients as a clinician and pursuing systemic change through grassroots economic development projects.

Sean McClellan, a 2017 Pisacano Scholar, is a fourth-year medical student at Rush Medical College. He graduated from

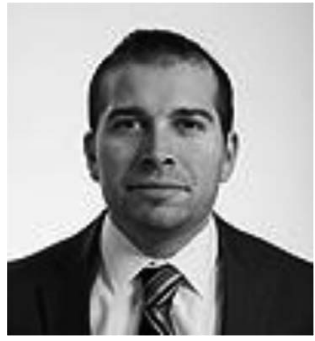
the University of Chicago with a Bachelor of Arts in Anthropology and was inducted into Phi Beta Kappa his junior year.

As a college student, Sean spent a year with Health Leads, a national organization of college students dedicated to understanding the socioeconomic barriers that lead to poor health and helping patients overcome them. He also volunteered for 3 years with STRIVE, a mentoring and support program for youth with sickle cell disease at a local children's hospital. Sean received a grant from the Human Rights Program at the University of Chicago to work with Primeros Pasos, a medical nongovernmental organization (NGO) that operates a clinic in rural, indigenous areas of Guatemala. As a 
development intern, Sean updated the Web site, organized and presented 6 years of malnutrition data from local schools, and with supervision researched and wrote a grant application to expand the women's health program. As a health educator, he taught daily lessons to elementary school children focusing on nutrition and hygiene.

After graduating from college, Sean became involved with Undocumented Illinois, a Chicago grassroots organization led by undocumented youth working toward the recognition of the rights and contributions of all immigrants. He helped plan rallies, marches and other political actions in Chicago and across the country, spoke at workshops for undocumented youth at high schools, organized lobbying bus trips, worked on campaigns to stop individual deportation cases, and wrote grant applications. During the summer following graduation, Sean was part of the logistics team for a 6-week national immigrant rights bus tour cosponsored by Undocumented Illinois. Since beginning medical school, Sean has continued his involvement with the group.

As the recipient of a Fulbright Program Research Fellowship, Sean spent a year before medical school exploring the intersections of health and popular politics in Guatemala and conducting fieldwork with a Mayanist association of health promoters, the national health care workers' union and an environmental NGO that supports communities affected by mining projects. Sean also received the Clarissa D. Haffner Family Practice Endowed Scholarship, a 3-year scholarship awarded annually to a student at Rush University who demonstrates a commitment to leadership within the field of family medicine. At Rush, Sean has been involved with the Latino Medical Students Association, Family Medicine Leads Emerging Leaders Institute and currently with the Illinois Academy of Family Physicians (IAFP) Government Affairs Committee. This past year Sean served as the Student President Elect for the IAFP.

After residency Sean would like to work at an Federally Qualified Health Center (FQHC) in Chicago and continue to build relationships with community organizations to address social determinants of health.

Franklin Niblock, a 2017 Pisacano Scholar, is a fourth-year medical student at the University of North Carolina School of Medicine (UNC). He graduated from UNC with a Bachelor of Science in

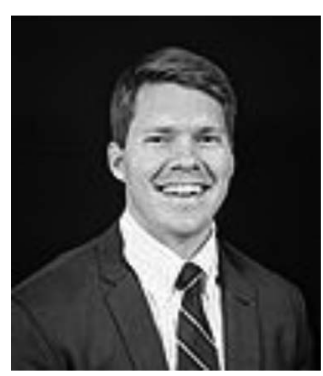

Health Policy and Management, and just completed his Master of Public Health at UNC's Gillings School of Global Public Health.

As an undergraduate, Franklin volunteered with Habitat for Humanity, coordinating international work-trips to Thailand and Honduras. As president of his Habitat for Humanity Campus Chapter, Franklin led fundraising efforts, helped recruit volunteers, and managed community partnerships to build homes for employees of his university, recognizing the need for affordable housing in the surrounding community. During the year he served as president, the organization was named National Campus Chapter of the Year.

Before medical school Franklin worked as a Project Coordinator for the North Carolina Office of Rural Health. In this position he performed a feasibility analysis of direct-payment systems for rural health clinics, implemented this system in a pilot clinic, and disseminated the model to rural health centers across the state. His experience solidified his interest in family medicine and provided him with a transformative professional experience in primary care. Subsequently, Franklin became a founding member and the program evaluator for MedServe, a student-run not-for-profit exposing recent college graduates to primary care medicine in rural and underserved North Carolina. Last year, he was inducted into the Eugene S. Mayer Community Service Honor Society for his involvement with MedServe.

During his first year of medical school Franklin was named a Primary Care and Population Health Scholar. This scholarship is awarded to students interested in practicing cost-effective, high-quality primary care as part of a larger vision of improving the health of populations. Franklin has been involved with the Public Health Interest Group and the Health Policy Interest Group, serving as Chair for both organizations. He also served on the North Carolina Academy of Family Physicians' Board of Trustees. His medical school research has focused on the influence of health literacy on the use of mobile health technology in the management of chronic disease. Franklin's work has been presented at conferences held by the American Diabetes Association and 
the North American Primary Care Research Group. Last year he received the Frank Lee Dameron Award from the Whitehead Society of the UNC School of Medicine, recognizing his commitment to practicing primary care medicine in a medically underserved area of North Carolina.

Franklin plans on training in full-spectrum family medicine while cultivating his interest in public health and systems of care. He intends to pursue a career in community-based family medicine, where he will aim to leverage the existing public health and health care infrastructure to reach underserved populations.

Robert Rock, a 2017 Pisacano Scholar, is a fourth-year medical student at Yale University School of Medicine. He gradu-

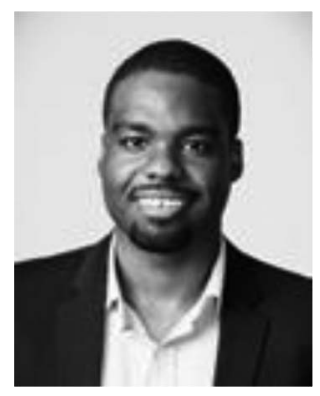
ated cum laude from New York University (NYU) with a Bachelor of Arts in Art History and in the premedical track.

As a graduating senior Robert received an award for his outstanding service to the Opportunity Programs at NYU. He founded and led a mentoring initiative for students within the Higher Education Opportunities Program and the Collegiate Science and Technology Entry Program. As a result of his commitment and initiatives, 6 years later the mentoring program has expanded through successive generations of student leadership. Robert also served as president of the Haitian American Student Association and volunteered with Operation Dream Catchers. As a team leader, Robert helped raise funds and collect medical supplies, which he helped deliver during 32 -week delivery missions to the Berbice Region of Guyana, where his team also presented health education lectures on chronic disease management.

While at the Yale School of Medicine, Robert served as the Community Service Liaison and then as Co-President for the Student National Medical Association and Latino Medical Student Association. Pursuing his passion regarding the role of social justice in medicine, Robert codeveloped an elective course in social medicine, domestic health equity, and health advocacy, called US Health Justice, for Yale medical students, nursing students, and physician associate students. He has also col- laborated with representatives across other professional schools at the university to form a multidisciplinary US Health Justice Collaborative, working to bring relevant programming and dialog across the campuses. As a result of these efforts, Robert was invited to sit on the Dean's Committee on Diversity, Inclusion and Social Justice, and currently serves as the Co-President of the United States Health Justice Collaborative. Robert is the creator and coordinator of Making the Invisible Visible: Art, Identity \& Hierarchies of Power. Originally part of the US Health Justice elective course, this guided art tour and reflection session is now part of the first master course for all entering medical students. The tour explores the expression of bias in Western culture and its effect on patient-provider interaction using art at the Yale Center for British Art and the Yale University Art Gallery. The tour has also been incorporated into the curriculum for the internal medicine residency program as well as the National Clinic Scholars Program at the Yale School of Medicine.

Robert's passions exist at the intersection of the arts, education, and health justice. His ultimate goal is to work as a primary care family physician in a neighborhood health center that doubles as a community center for the arts and education in service to promoting population health in the area. In this vibrant space, Robert hopes to pursue policy-driven community-based participatory research where interdisciplinary teams partner with community groups to advocate for policy changes that directly affect their health.

Dev Vashishtha, a 2017 Pisacano Scholar, is currently a fourth-year medical student at UC San Diego. He graduated

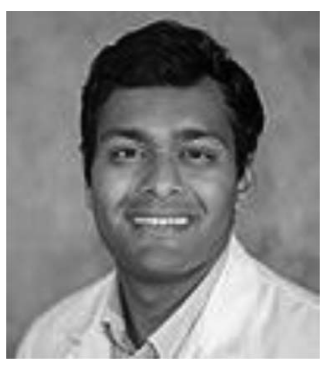
summa cum laude from UC San Diego with a Bachelor of Arts in Political Science and a minor in Biology. Dev completed his Master of Advanced Studies in Clinical Research at the UC San Diego School of Medicine, during which time he was funded by a $\$ 30,000$ National Institutes of Health TL-1 training grant.

As an undergraduate, Dev was a Regents Scholar and Medical Scholar, received multiple Provosts' 
Honors, and was inducted into the Muir College Caledonian Society and the Phi Beta Kappa national political science honors society. As a volunteer with South Asian Health Initiative, Dev cofounded and led a community-level diet and exercise intervention funded through the American College of Physicians. His work was highlighted at the Clinton Global Heath Initiative in 2011 and 2012.

Before medical school, Dev lived with his grandparents and studied Indian Classic Vocal Music in Chennai, India for 1 year. After beginning medical school, he completed an internship at the California State Capitol under Assemblywoman Lorena Gonzalez. During this internship Dev contributed to a fact sheet on the Healthy Workplaces, Healthy Families Act of 2014 (AB 1522), which provided paid sick leave to millions of workers across California. Governor Jerry Brown read this fact sheet before signing $A B 1522$ into law. Dev has traveled to Sacramento multiple times as part of California Medical Association delegations. Dev is also a student member of the CAFP Board and the Foundation Board of Trustees. He serves as a Key Legislative Contact for the CAFP, and he advocates for greater ethnic and gender diversity in organized medicine and for primary care-centered payment reform.

Through Physicians for Social Responsibility, Dev lobbied in Washington, DC for President Obama's Clean Power Plan. He was also 1 of the founding members of the 2015 Hindu Declaration on Climate Change and created a monthly UC San Diego lecture series on Human Health and Climate Change. For his commitment to leadership in environmental issues, Dev was awarded the national Switzer Foundation Environmental Fellowship.

As a clinical researcher Dev has published numerous peer-reviewed abstracts and journal articles in the fields of injection drug use, environmental health and cardiovascular epidemiology. He aspires to be a compassionate, full-spectrum family medicine clinician, researcher and policy maker working to improve community health and wellbeing. Dev is passionate about recruiting medical students into family medicine. Eventually, he intends to run for political office.

To see this article online, please go to: http://jabfm.org/content/ 30/6/849.full. 